\title{
La política agrícola de Filipinas
}

I ntroducción

Una de las macrotendencias del desarrollo económico es la disminución en la importancia relativa del sector agrícola, frente a otros sectores de la economía. Esto es, con el crecimiento económico, los sectores industrial y de servicios se vuelven más importantes en términos de su participación en el producto interno bruto; disminuye la mano de obra ocupada en el sector primario y se reduce la población en las zonas rurales. Para alimentar a la creciente población de las ciudades, es común el rápido desarrollo de nuevas técnicas de producción agrícola, que se refleja en un creciente volumen de bienes y en una mayor productividad, tanto por unidad de superficie cultivada, como por unidad de trabajo invertido. La capitalización del campo y la disminución de la pobreza rural son consustanciales a este proceso.

Este esquema, que dista mucho de ser un tipo ideal weberiano puesto que es común encontrarlo en la realidad, en algunos casos no opera o funciona de manera parcial. En el caso de Filipinas se presenta de la siguiente manera: la disminución relativa de la agricultura frente a otros sectores de la economía no ha propiciado una disminución sustantiva de la mano de obra ocupada en el campo; el aumento en la producción y la productividad agrícola han sido inferiores al crecimiento de la población y la capitalización ha sido muy poco significativa; el resultado es el aumento de la pobreza rural y la disminución en cuando a seguridad alimentaria. ¿Cómo se puede explicar esta situación? Aunque, en principio podría afirmarse que el problema es de carácter multifactorial, una de las causas principales está en la política agrícola.

* Investigador del Departamento de Estudios del Pacífico de la Universidad de Guadalajara.

ORCID http://orcid.org/0000-0002-9145-5865
Aunque Filipinas posee una escasa dotación de recursos naturales y agrícolas per cápita, ésta no es muy diferente de la de otros países del sudeste de Asia, que han refuncionalizado su agricultura (Mya Than 1998). De acuerdo con datos de la FAO (FAOSTAT), de un total de 11.2 millones de hectáreas con vocación agrícola, 5.5 millones se encuentran bajo cultivo, y de éstas 1.5 millones están bajo el sistema de riego. La dotación de tierra cultivable per cápita es de 0.15 hectáreas (1997). Durante los noventa la frontera agrícola se mantuvo sin cambios, mientras que por otra parte la población creció 2.2 por ciento anual.

El estancamiento agrícola no podría atribuirse a la falta de crecimiento económico. Si bien en los últimos años ha diminuido en cuanto a la tasa de crecimiento del PIB, aún en los años en que el crecimiento económico ha sido significativo (de alrededor de 5 por ciento del PIB anual a mediados de los noventa), ello no se ha reflejado en un aumento significativo de la producción agrícola ni en una mejoría para la población rural.

La agricultura de Filipinas continúa representando una parte muy significativa del PIB. Como se muestra en el cuadro 1, el PIB agrícola que en 1965 era de 31.5 por ciento, para 1994 aún alcanzaba 21.8 por ciento y para 1999 18 por ciento; la población económicamente activa (PEA) en la agricultura, que en 1965 representaba 58.6 por ciento de la PEA total, para 1994 aún representaba 46 por ciento.

Esto significa que el crecimiento de los otros sectores económicos ha sido insuficiente para absorber la mano de obra rural, y que el crecimiento de la población ha sido mayor que los incrementos en el producto y la productividad agrícolas, lo que en buena medida explica el incremento del minifundio y la pobreza. Por otra 
Cuadro 1

Filipinas: la agricultura en la economía nacional, 1965-1995

\begin{tabular}{lrrrrrrrrr}
\hline & 1965 & 1975 & 1985 & 1990 & 1995 & 1996 & 1997 & 1998 & 1999 \\
& & & & & & & & & \\
& & & & & $1,084.4$ & $1,185.2$ & $1,151.3$ & 892.6 & 1018.4 \\
PIB per cápita (en US\$)* & & & & & & & & & \\
& & & & & & & & & \\
Proporción (\%) de la agricultura en: & 31.5 & 26.9 & 28.6 & 27.0 & 21.8 & 21.1 & 19.8 & 18.5 & 18.0 \\
$\quad$ PIB & 58.6 & 56.7 & 48.9 & 45.1 & 42.4 & 41.8 & 41.2 & 40.5 & 40.0 \\
$\quad$ Empleo (PEA)
\end{tabular}

* Calculado con base en datos de la FAO, FAOSTAT (http://apps1.fao.org/) y FMI, Estadísticas financieras internacionales.

Fuente: Balisacan, 1998: 78; FAO, FAOSTAT (http://apps1.fao.org/) .

parte, al darse un mayor crecimiento de la población que de la producción agrícola, tienen que crecer las importaciones de alimentos. Como se aprecia en el cuadro 2, la relación entre importaciones y exportaciones agrícolas tiende a ser cada vez más negativa. La relación entre importaciones y exportaciones, que en 1990 era de 0.85 , disminuyó a 0.72 en 1997 . Esta relación continúa deteriorándose; los niveles de producción agrícola de 1997 apenas se han recuperado en 1999 y 2000 , después de 1998 que fue catastrófico.

El uso de tecnología agrícola está poco desarrollado, aún la de carácter básico. Con excepción del uso de fertilizantes, que creció en 40 por ciento entre 1991 y 1998 al pasar de 447818 a 628930 toneladas, el uso de cosechadores (700) y tractores agrícolas (11 000) permaneció estancado durante el decenio de los noventa (FAO).

La producción agrícola, en 1998, sufrió un serio descalabro: disminuyó en 135 por ciento en relación con el año anterior. Las razones principales de esta disminución se atribuyen a las condiciones climatológicas adversas provocadas por El Niño y los fuertes tifones que golpearon las costas de Filipinas, durante el último trimestre del año. Específicamente, la producción de arroz disminuyó en 24.1 por ciento y la de maíz en 11.8 por ciento. Otros sectores, como el ganadero y el pesquero, resultaron menos perjudicados: el primero mostró una tasa de crecimiento de 4.1 por ciento y el segundo de 2 por ciento (PECC 2000: 79).

De acuerdo con datos de la FAO, para 1999 la producción agrícola prácticamente se había recuperado. Como se muestra en el cuadro 3, la producción de cereales en 1997 casi alcanzó los 15.6 millones de toneladas; las de arroz y maíz fueron ligeramente superiores: de 11.7 y 4.6 millones, respectivamente. Sólo la producción de frutas se mantuvo estancada en 10 millones detoneladas.

Debido a la disminución en la producción, en 1998, las importaciones de cereales y granos forrajeros se incrementaron en 57.2 por ciento

Cuadro 2

Filipinas: índices de comercio exterior agrícola, 1990-1997 (valor 1989-1991=100)

\begin{tabular}{|c|c|c|c|c|c|c|c|c|}
\hline & 1990 & 1991 & 1992 & 1993 & 1994 & 1995 & 1996 & 1997 \\
\hline $\begin{array}{l}\text { Importación total de productos agrícolas } \\
\text { (en valor } 1989-1991=100)\end{array}$ & 116 & 86.0 & 105.0 & 117.0 & 149.0 & 190.0 & 224 & 201 \\
\hline $\begin{array}{l}\text { Exportación total de productos agrícolas } \\
\text { (en valor } 1989-1991=100)\end{array}$ & 99 & 102.0 & 113.0 & 109.0 & 116.0 & 155.0 & 142 & 144 \\
\hline Diferencia: exportación/importación & 0.85 & 1.19 & 1.08 & 0.93 & 0.78 & 0.82 & 0.63 & 0.72 \\
\hline
\end{tabular}

Fuente: FAO, FAOSTAT (http://apps1.fao.org/). 
Cuadro 3

Filipinas: producción agrícola. Productos seleccionados

(miles de toneladas)

\begin{tabular}{lrrrrr}
\hline & 1995 & 1996 & 1997 & 1998 & 1999 \\
\hline $\begin{array}{l}\text { Cereales } \\
\text { Crecimiento anual }\end{array}$ & $14,701,992$ & $15,628,600$ & $15,600,420$ & $12,377,184$ & $16,403,000$ \\
& & 6.30 & $(0.18)$ & $(20.66)$ & 32.53 \\
$\begin{array}{l}\text { Arroz } \\
\text { Crecimiento anual }\end{array}$ & $10,540,640$ & $11,283,570$ & $11,268,000$ & $8,554,000$ & $11,760,000$ \\
& & 7.05 & $(0.14)$ & $(24.09)$ & 37.48 \\
$\begin{array}{l}\text { Maíz } \\
\text { Crecimiento anual }\end{array}$ & $4,161,330$ & $4,345,010$ & $4,332,420$ & $3,823,184$ & $4,643,000$ \\
& & 4.41 & $(0.29)$ & $(11.75)$ & 21.44 \\
$\begin{array}{l}\text { Frutas primarias } \\
\text { Crecimiento anual }\end{array}$ & $9,516,115$ & $9,823,315$ & $10,543,378$ & $10,024,420$ & $10,024,420$ \\
& & 3.23 & & & \\
\end{tabular}

Fuente: FAO, FAOSTAT (http://apps1.fao.org/).

y 35.9 por ciento, respectivamente, en comparación con 1997.

La significativa depreciación del peso (de 50 por ciento en mayo de 1997) ha tenido efectos positivos en las exportaciones agrícolas de Filipinas. En 1998, las exportaciones de aceite crudo de coco y coco seco se incrementaron en 40 por ciento y 15.7, respectivamente, sobre los niveles de 1997. Los precios de las exportaciones de camarón aumentaron en 39 por ciento, el plátano en 12 por ciento y para las piñas enlatadas en 27.5 por ciento; para el azúcar centrifugada en 44.7 por ciento y para el atún preparado en 22.4 por ciento (PECC 2000: 79).

\section{La política agrícola actual}

Consciente el régimen político de que la mayor parte de los pobres del país se encuentran en las zonas rurales, su intención sobre el desarrollo agrícola tiene como objetivo la disminución de la pobreza, mejorar la seguridad alimentaria y propiciar un desarrollo agrícola sustentable. Hay que recordar que más de 40 por ciento del total de la población filipina dependen de la agricultura para su supervivencia (Alexander 1998: 1).

La política agrícola de Filipinas se define mediante la aprobación de leyes específicas. La Ley de Modernización Agrícola y Pesquera de 1997 (LMAP) reporta entre sus objetivos fundamentales "incrementar la productividad y hacer frente al reto de la globalización”. Para ello, la Ley prescribe un conjunto de medidas urgentes, entre las que se cuentan el desarrollo de la infraestructura rural y el fortalecimiento del empleo no agrícola para la población rural (PECC 2000: 80). 
Esta ley da prioridad a las facilidades de irrigación, al destinar 30 por ciento del presupuesto agrícola a esta actividad. Se pretende incrementar la cantidad de tierra irrigada, de 1.4 millones de hectáreas a 2 millones, lo que permitirá al país ser autosuficiente en la producción de arroz, así como diversificarse hacia otros productos, sobre los cuales Filipinas posee una ventaja comparativa.

En el programa de construcción de infraestructura son incluidos los caminos campo-mercado, los puertos de embarque, las facilidades de comunicación y otras facilidades que darían acceso a las áreas rurales y a los insumos para la producción agrícola, información tecnológica y crédito.

La ley define $y$ prescribe un amplio programa de educación y entrenamiento que podría "acelerar el progreso social, promover la liberalización y el desarrollo humano total, y el pleno empleo con base en el desarrollo de la agricultura y la pesca”.

La LMAP afirma también la necesidad de desarrollar un programa de empleo no agrícola que "emplee a los trabajadores eficientemente en las áreas rurales para mejorar sus niveles de vida y reducir su propensión a migrar hacia las áreas urbanas".

Además de la modernización, la Reforma Agraria representa otro ingrediente fundamental en los esfuerzos de desarrollo rural del régimen de Estrada. Mediante el Programa de Reforma Agraria Integral (PRAI) se pretenden establecer las bases sociales del desarrollo agrícola. El PRAI incluye el mejoramiento de la tenencia de la tierra, el desarrollo rural comunitario sustentable y equitativo, así como la justicia agraria.
El mejoramiento de la tenencia de la tierra considera la adquisición y la distribución de parcelas entre los campesinos sin tierra, así como la protección del sistema de tenencia al través de la ejecución de los contratos de arrendamiento.

Para junio de 1998, de acuerdo con el Departamento de la Reforma Agraria (DRA), se habían distribuido 57 por ciento de los 8.1 millones de hectáreas destinadas al reparto agrario. $\mathrm{El}$ remanente 43 por ciento, que equivale a 3.5 millones de hectáreas, consistía en 1.6 millones de hectáreas de propiedad privada y 1.9 millones de hectáreas de tierras agrícolas públicas. El régimen ha manifestado su intención de completar el PRAI para junio de 2002, aunque la Ley (R.A.8532), extiende la aplicación del programa hasta el 2008 (Alexander 1998: 2).

El programa de desarrollo rural comunitario sustentable y equitativo ha avanzado en más de 50 por ciento; sin embargo, ha tenido un impacto poco significativo sobre el campo filipino, de acuerdo con el DRA. La mayor parte de las tierras distribuidas han sido tierras públicas con muy pocas posibilidades de inversión para el desarrollo de infraestructura y tecnología. Con el objeto de optimizar los limitados recursos financieros, el DRA ha adoptado una perspectiva de áreas integradas de desarrollo, enmarcadas en una estrategia de desarrollo autoadministrado por medio de Comu-nidades de Reforma Agraria. En estas áreas el DRA espera intensificar su intervención para ayudar a los agricultores a incrementar su producción agrícola y su ingreso, involucrándose en agricultura sustentable y participación en los gobiernos locales.

La Oficina de Servicios de Apoyo del DRA se ha involucrado en la construcción de 
infraestructura social y otorgamiento de servicios al nivel de base. El Departamento de la Reforma Agraria asigna también extensionistas al nivel de comunidad. En este sentido, el DRA participa en trabajos de desarrollo de infraestructura como irrigación, facilidades poscosecha y caminos sacacosechas; en otorgar créditos a los pequeños agricultores y organizaciones campesinas; en proveer de asistencia financiera a industrias pequeñas y de media escala; en investigación y desarrollo; en asesorar sobre administración de cooperativas, y en otorgar asistencia sobre comercialización.

La prestación de justicia agraria involucra la resolución de casos de reforma agraria y conflictos entre campesinos y terratenientes y entre grupos de campesinos. Este componente, por ejemplo, cubre la determinación de valores de las tierras que son adquiridas bajo el Programa de Reforma Agraria Integral (Alexander 1998: 3).

Aunque el sector rural ofrece mucho espacio para el crecimiento, décadas de abandono, como lo evidencian los bajos niveles de inversión han detenido el desarrollo. No obstante las tasas de crecimiento económico alcanzadas a mediados de los noventa, el crecimiento de la agricultura fue de sólo 2 por ciento. Existen cuatro preocupaciones del DRA y de la población en general sobre el Programa de Reforma Agraria Integral: el bajo nivel de recursos financieros, la lenta resolución de los casos agrarios, la reglamentación sobre el usufructo de la tierra y el agua, y las violaciones a la ley de reforma agraria.

En la actualidad, la insuficiencia de los recursos financieros dificulta los esfuerzos gubernamentales para llevar a la práctica las medidas de la Ley de Modernización Agrícola y Pesquera y de la Reforma Agraria en particular. La asignación de P\$50 000 millones para los próximos 10 años (hasta 2008) es insuficiente; el DRA calcula que se requieren $\mathrm{P} \$ 111000$ millones. El sector privado se muestra renuente a invertir en estos proyectos mientras no exista una más clara definición de las políticas gubernamentales y aceptación pública del uso de los recursos para las facilidades de infraestructura. El gobierno, por su parte, espera acudir al Banco Mundial y al Banco Asiático de Desarrollo para apalancar el financiamiento del desarrollo de la infraestructura (PECC 2000: 80; Alexander 1998: 4).

Actualmente, la agricultura filipina se encuentra en dificultades para competir en una economía globalizada. Las tasas de crecimiento de la producción agrícola han bajado de un promedio anual de 5.8 por ciento en los setenta a 2 por ciento en los ochenta y los noventa, por debajo de la tasa de crecimiento de la población que es de 2.3 por ciento.

La tierra arable disponible para usos agrícolas continúa disminuyendo, al grado de que las actividades agrícolas ya no proveen de un adecuado ingreso para la población del campo. El ingreso no agrícola de las familias rurales ahora alcanza aproximadamente 40 por ciento de su ingreso total y continúa aumentando. Debido a la inadecuada infraestructura rural, es en ocasiones más barato transportar las mercancías desde el exterior hacia las áreas de consumo que desde las áreas remotas de producción dentro de Filipinas. Los servicios de apoyo agrícola, incluyendo la investigación y desarrollo, la extensión y el crédito son inadecuados para hacer frente a los requerimientos de la población rural (PECC 2000: 80).

La pobreza rural en Filipinas es evidente: tres cuartas partes de las familias pobres se ubican en las áreas rurales.

\section{Conclusiones}

Los enunciados sobre la política agrícola de Filipinas ponen de manifiesto que no basta con mencionar y describir lo que debería hacerse para desarrollar el campo y mejorar el nivel de vida de la población. Lo más importante es establecer los mecanismos viables para su realización. "La experiencia del desarrollo agrícola de Filipinas, en la segunda mitad del siglo XX, ilustra cómo las políticas erróneas y los factores institucionales pueden constreñir las 
respuestas de las áreas rurales a los estímulos del crecimiento agrícola y de este modo contribuir a entorpecer el desarrollo económico" (Belisacan 1998: 77).

El crecimiento económico en general y el crecimiento del sector agrícola en particular no traen consigo, necesariamente, un alivio en la pobreza rural, sino más bien una polarización de la riqueza. El alivio de la pobreza requiere de políticas específicas, relacionadas con el apoyo al aumento en la producción y la productividad de la agricultura. De los agricultores: empresariales, pequeña propiedad y explotación colectiva.

La liberalización por sí misma no resuelve los problemas que dejó pendientes la etapa de mayor participación gubernamental. Esta última beneficia algunos grupos cercanos al régimen. La situación para la mayoría de la población no cambia. La liberalización requiere la creación de condiciones específicas para la inversión privada; la certidumbre en la tenencia de la tierra es uno de los requisitos básicos.

Mientras no aumente la productividad, el incremento en la producción dependerá de la incorporación de nuevas áreas al cultivo. Pero si no es redituable trabajar las nuevas tierras, por falta de infraestructura, crédito y transporte, sólo se pospone un problema.

El desarrollo es fundamentalmente un proceso endógeno. Los factores positivos externos pueden contribuir al progreso, pero mientras no existan políticas, lineamientos y programas viables, el desarrollo continuará esperando.

\section{Fuentes}

Alexander, T. Charles (1998) "Philippine Comprehensive Agrarian Reform Program”, Report AGR Number RP8055, Embajada de los EE.UU; Balisacan M. Arsenio (1998) "Policy Reforms and Agricultural Development in the Philippines", ASEAN Economic Bulletin, April 1998; FAO, FAOSTAT; Mya Than (1998) "Development Strategies, Agricultural Policies and Agricultural Development in Southeast Asia”, en ASEAN Economic Bulletin, vol. 15, núm. 1, abril de 1998.

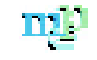

